\title{
A Biological Objection to Evolution
}

\author{
Samuel A. Nigro, M.D. \\ Retired, Assistant Clinical Professor Psychiatry, Case Western \\ Reserve University School of Medicine, USA \\ sam@docnigro.com
}

Received Date: June 03, 2017

Accepted Date: July 1, 2017

Published Date: July 13, 2017

The very same biology used to allegedly "prove" evolution disproves it moreso. This has to do with the planetary ecology of sex: Essentially, all sexuality and mating for all subhuman animals is pheromone dependent and consistent with reproduction. Indeed, humans are the only creatures not pheromone dependent for mating. Humans are free from pheromone control and thus even in sexuality can humans pollute by rejecting Nature and natural function--just as with almost everything else humans do (It must have something to do with original sin). Humans pay little attention to Nature until a real mess is created. Without pheromone control, humans do not have Nature's standards for animals and are therefore indiscriminate and anti-ecological in sexual activity alleging "freedom" when, of course, it is merely that humans can again choose against nature and even use the reproductive system for something other than its natural purpose of reproduction. Without pheromone control, humans become seduced by glitzy degrading sex-as-recreation contrary to natural function, thusly polluting the planet even in biological behavior perhaps appropriately called "sexcretion" because it sure is not reproduction as for the rest of the animal kingdom and Nature. If we forced animals to treat sex like we do, it would be animal cruelty. For humans, sex outside of reproduction and unition in marriage is actually nothing but excretion-accurately called "mutual toileting."

And, without a doubt, this overlooked pheromone independence of humans has been projected onto the animal kingdom thus resulting in the theory of evolution, because evolution as currently conceived is only possible if subhuman animals do not have pheromones. Au fond, evolution is a psychotic interpretation and projection of human pheromone independence onto the animal kingdom. It is psychotic because pheromone independence for subhuman animals is a delusion.

One will never find or see subhuman animals in sexual activity or mating that is not with a like animal having matching pheromones, although infrequently subhuman animals also have mental illnesses and idiosyncratic events. Homosexuals have exaggerated all non-mating animal idiosyncrasies and illnesses, especially in 2 books: Biological Exuberance: Animal Homosexuality and Natural Diversity by Bruce Bagemihl and Evolution's Rainbow: Diversity, Gender, and Sexuality in Nature and People by Joan Roughgarden-Neither book lists "pheromone" in the index, and it is obvious that the authors likely never heard of pheromones rendering both books to be unscientific propaganda, because it is fraud to discuss animal sexuality without consideration of pheromones (Reviews of both books are available and may accompany this article). Incontrovertibly, pheromones mean that mating (sexual activity) is reproduction consistent activity with a mature opposite sex member of the same species. PERIOD.

In terms of "evolution," pheromones mean there will not be mating of different species, and thus there are no natural hybrids in nature. There can be genetic adaptive alterations in a species as described by Darwin, but there are no major cross species mating or "miscegnation" (for want of a better word). If the pheromones do 


\section{A Biological Objection To Evolution}

not match, there will be no mating! Thus the whole large genetic interplay and multiple gene transferring required by evolution for major species creation and change is a fantasy because different species do not mate and there will be no hybrids in Nature.

In addition, from what we know about forced hybridization done by human manipulation of fairly similar species (to mules or tigrons, for examples), the resulting created hybrid animals cannot reproduce, likely because of non-matching meiosis, and there goes evolution down the drain again. Thus, even if there were natural hybrids, science shows they cannot reproduce! It is a fantasy that cross-breeding results in "new" greatly changed species.

So there you have it: In nature, there is no mating without pheromone matching; there are no animal hybrids in nature; and artificially created animal hybrids are sterile and cannot reproduce. These are scientific facts. Thus, there is no major species changing evolution as dogmatically demanded, and it is unscientific to believe in it. Tell your friends!

It is worth repeating that Religion can live with evolution or without it. In fact, religion lays claim to ecological soundness by the "psychosocial pheromones" from the Roman Catholic Church-the only organization in the world promoting human sex consistent with Natural Law and Transcendental Love (The psychosocial pheromone from the Church is known as "matrimony.").

In contrast, however, atheists cannot live without evolution ...which is science fiction and a myth as currently promoted.

For biologists, evolutionists, and atheists, their problem is real science. They ought to go to Mass once in awhile. (see attachment).

Citation: Samuel A. Nigro, M.D. “A Biological Objection To Evolution”. American Research Journal of Neurology; V1, I1; pp: 1-2

Copyright (c) 2017 Samuel A. Nigro, M.D. This is an open access article distributed under the Creative Commons Attribution License, which permits unrestricted use, distribution, and reproduction in any medium, provided the original work is properly cited. 